\title{
Modified Glasgow Prognostic Score 2 as a Prognostic Marker in Patients With Metastatic Urothelial Carcinoma
}

\author{
TAKASHI NAGAI ${ }^{1}$, TAKU NAIKI $^{1}$, TERUKI ISOBE $^{1}$, YOSUKE SUGIYAMA $^{2}$, TOSHIKI ETANI $^{1}$, \\ KEITARO IIDA $^{1}$, SATOSHI NOZAKI ${ }^{1}$, YUSUKE NODA ${ }^{1,3}$, NOBUHIKO SHIMIZU ${ }^{1}$, \\ YOSHIHIKO TASAKI ${ }^{2}$, YOSHIHISA MIMURA ${ }^{2}$, RIKA BANNO ${ }^{4}$, HIROKI KUBOTA ${ }^{5}$, \\ SHUZO HAMAMOTO $^{1}$, NORIYASU KAWAI ${ }^{1}$ and TAKAHIRO YASUI ${ }^{1}$ \\ ${ }^{1}$ Department of Nephro-urology, Nagoya City University, Graduate School of Medical Sciences, Nagoya, Japan; \\ ${ }^{2}$ Department of Pharmacy, Nagoya City University Hospital, Nagoya, Japan; \\ ${ }^{3}$ Department of Urology, Toyota Kosei Hospital, Toyota, Japan; \\ ${ }^{4}$ Department of Urology, Konan Kosei Hospital, Konan, Japan; \\ ${ }^{5}$ Department of Urology, Kainan Hospital, Yatomi, Japan
}

\begin{abstract}
Background/Aim: Predicting the prognosis of metastatic urothelial carcinoma $(\mathrm{mUC})$ patients is needed for clinical decisions. We examined the value of a modified Glasgow prognostic score ( $m G P S)$ as a predictive marker for mUC patients. Patients and Methods: In a multicenter study, 68 mUC patients received short hydration gemcitabinel cisplatin (shGC) and 74 received pembrolizumab (PEM). Patients were allocated according to $m G P S$. Progression-free (PFS) and cancer-specific (CSS) survival were examined. Results: Higher $m G P S$ reflected poorer PFS and CSS in $\operatorname{shGC}(p=0.03, p<0.0001$, respectively) and PEM ( $p=0.02$, $p<0.001$, respectively) patients. PFS for the high $m G P S$ group was longer than that of the low mGPS group in the two cohorts $(p<0.0001$ for both), with similar CSS results $(p<0.0001$ and $p<0.001$, respectively). Multivariate analyses revealed high $m G P S$ was a risk factor for poor CSS in both cohorts $(H R=3.55, \quad p<0.001$, and $H R=2.21, \quad p<0.01$, respectively). Conclusion: In the $m U C$ patients receiving shGC or PEM, mGPS was a predictive prognostic marker.
\end{abstract}

The incidence of bladder cancer is rising but the mortality rate has recently become reduced with improved treatment

This article is freely accessible online.

Correspondence to: Taku Naiki, MD, Ph.D., Department of Nephrourology, Nagoya City University, Graduate School of Medical Sciences, Kawasumi 1, Mizuho-cho, Mizuho-ku 467-8601, Nagoya, Japan. Tel: +81 528538266, Fax: +81 528533179, e-mail: naiki@med.nagoya-cu.ac.jp

Key Words: Metastatic urothelial carcinoma, modified Glasgow prognostic score, biomarker, prognosis.
(1). However, for patients with metastatic urothelial carcinoma (mUC) the 5-year survival rate is approximately $5 \%$ and its prognosis appears poor (2). Evidence from several regimens has been used to improve the prognosis of mUC. Cisplatin-based chemotherapy is recommended as first-line treatment for mUC in National Comprehensive Cancer Network (NCCN) guidelines $(3,4)$. For decades, evidence from second-line therapy has been lacking. Recently, the efficacy of pembrolizumab (PEM) was described (5), which became the preferred regimen of second-line therapy for mUC under NCCN guidelines (4). However, the optimal timing of a switch in drug has not been established and a definitive prognostic marker for supporting drug selection is lacking. In this regard, useful biomarkers have appeared to assist physicians in identifying the timing of the cessation of the administration of drugs that lost their efficacy over time in patients with advanced cancers.

Several evaluation methods related to nutrition or inflammation have been identified that can be used to assess the prognosis of cancer patients. Useful prognostic markers for mUC based on drugs have been reported previously. Predictive factors for the prognosis of patients with mUC who received cisplatin-based chemotherapy are: performance status (PS), hemoglobin levels, and liver metastasis (6). Sarcopenia, a quantitative measure of a loss in muscle mass and strength, is as a prognostic marker of patients with mUC who received gemcitabine and cisplatin (GC) (7). In a previous report, we described how the progression of sarcopenia was also considered a predictive marker of overall survival as found in patients with mUC who underwent gemcitabine and docetaxel treatment as secondline therapy (8). In research on biomarkers using blood samples, the neutrophil-lymphocyte ratio was also shown to reflect the response of patients who showed muscle-invasive 
bladder cancer and who underwent chemotherapy that was neoadjuvant cisplatin-based (9). Such biomarkers have drawbacks and advantages, with the identification of patients with a very poor prognosis being difficult. In particular, albumin (Alb) is also known to reflect precise nutritional conditions. We previously reported that after stratification as two layers with one cut-off, a geriatric nutritional risk index, one of the albumin-based biomarkers, predicted the survival outcome of patients with mUC who received PEM (10). Recently, a Glasgow prognostic score (GPS) and modified GPS (mGPS), which are able to assess nutrition and inflammation, have also been considered as biomarkers with more stratification $(11,12)$. Such biomarkers are scores based on Alb and C-reaction protein (CRP) levels. By changing the cutoff of CRP to $0.5 \mathrm{mg} / \mathrm{dl}$, mGPS could be validated for Japanese people (12). Thus, we focused on the usefulness of mGPS for patients with mUC as a predictive marker of drug efficacy.

Recently, the utility of mGPS has been described in a meta-analysis in urological oncology (13). However, the preoperative or postoperative mGPS are considered useful markers based on prior reports. Importantly, no reports exist regarding the utility of $\mathrm{mGPS}$ for assessing therapeutic effects in the systemic treatment of mUC. We, therefore, evaluated the utility of mGPS in the prognosis of Japanese patients with mUC undergoing first- and second-line treatment in a multicenter retrospective study.

\section{Patients and Methods}

Study setting, patients and definitions. We set up two retrospective cohorts in a multicenter study at Nagoya City University Hospital and three affiliated institutions. One retrospective study was of patients with mUC administered short hydration GC (shGC) as firstline therapy from January 2016 to July 2020. The other was of patients who were administered PEM as second-line therapy from November 2016 to December 2019. Of these patients, 68 underwent shGC as first-line therapy, and 74 patients underwent PEM as second-line therapy. All patients were histologically diagnosed with urothelial carcinoma by transurethral resection of bladder cancer or cystectomy. Magnetic resonance imaging, computed tomography, and bone scintigraphy were also conducted to determine TNM stage based on the Union for International Cancer Control (8th edition). Patient follow-ups were conducted with regular radiological examinations, blood exams, cystoscopy, and urine cytology. The effects of therapy were evaluated based on Response Evaluation Criteria in Solid Tumors criteria (version 1.1). This study was conducted after being approved by our institutional review board (approval number: 60-18-0060). All patients supplied written informed consent.

Drug administration. Patients with shGC underwent first-line chemotherapy. The following was our original regimen, which was comparable with conventional GC (14): Patients were administered gemcitabine $\left(1,000 \mathrm{mg} / \mathrm{m}^{2}\right)$ on days 1,8 , and 15 , while cisplatin $(70$ $\mathrm{mg} / \mathrm{m}^{2}$ ) and 2,000 $\mathrm{ml}$ of fluid were given on the first day. The cycle
Table I. Comparison of patient characteristics in the first-line shGC treatment cohort.

\begin{tabular}{|c|c|c|c|c|}
\hline Characteristics & $\begin{array}{c}\text { mGPS } 0 \\
(\mathrm{n}=28)\end{array}$ & $\begin{array}{c}\text { mGPS } 1 \\
(\mathrm{n}=23)\end{array}$ & $\begin{array}{c}\text { mGPS } 2 \\
(\mathrm{n}=17)\end{array}$ & $p$-Value \\
\hline $\begin{array}{l}\text { Median age, } \\
\text { years (range) }\end{array}$ & $\begin{array}{c}73 \\
(53-87)\end{array}$ & $\begin{array}{c}75 \\
(49-86)\end{array}$ & $\begin{array}{c}66 \\
(54-81)\end{array}$ & 0.15 \\
\hline \multicolumn{5}{|l|}{ Gender, n (\%) } \\
\hline Male & $22(78.6)$ & $18(78.3)$ & $15(88.2)$ & 0.79 \\
\hline Female & $6(21.4)$ & $5(21.7)$ & $2(11.8)$ & \\
\hline \multicolumn{5}{|l|}{ Primary site, n (\%) } \\
\hline Upper urinary tract & $10(35.7)$ & $13(56.5)$ & $8(47.1)$ & 0.35 \\
\hline Bladder & $18(64.3)$ & $10(43.5)$ & $9(52.9)$ & \\
\hline $\begin{array}{l}\text { Median BMI, } \\
\mathrm{kg} / \mathrm{m}^{2} \text { (range) }\end{array}$ & $\begin{array}{c}21.8 \\
(17.4-32.0)\end{array}$ & $\begin{array}{c}22.1 \\
(15.1-33.8)\end{array}$ & $\begin{array}{c}20.6 \\
(13.3-25.5)\end{array}$ & $<0.05^{*}$ \\
\hline \multicolumn{5}{|l|}{ Metastatic site, n (\%) } \\
\hline Lymph node alone & $18(64.3)$ & $17(73.9)$ & $5(29.4)$ & $<0.05^{*}$ \\
\hline Visceral metastasis & $10(3$ & $6(26.1)$ & $12(70.6)$ & \\
\hline \multicolumn{5}{|l|}{ ECOG-PS, n (\%) } \\
\hline 0 & $25(89.3)$ & $20(87.0)$ & $10(58.8)$ & $<0.05^{*}$ \\
\hline 1 & $3(10.7)$ & $3(13.0)$ & $7(41.2)$ & \\
\hline $\begin{array}{l}\text { Objective response, } \\
\mathrm{n}(\%)\end{array}$ & $20(71.4)$ & $13(56.5)$ & $4(23.5)$ & $<0.01 * *$ \\
\hline $\begin{array}{l}\text { Median total cycles } \\
\text { of shGC, } n \text { (range) }\end{array}$ & $6(2-12)$ & $5(2-11)$ & $2(2-8)$ & $<0.01 * *$ \\
\hline
\end{tabular}

BMI, Body mass index; ECOG-PS, Eastern Cooperative Oncology Group Performance Status; mGPS, modified Glasgow prognostic score; shGC; short hydration gemcitabine and cisplatin. ${ }^{*} p<0.05, * * p<0.01$ statistically significant.

used was 28 days. Second-line therapy, PEM, was conducted after the failure of first-line cisplatin-based chemotherapy in this study. All patients were administered PEM intravenously (200 mg/body) every 3 weeks.

Clinical variables. The characteristics of patients and their progress were derived from patients' medical records. These included age, gender, body mass index, height, weight, tumor status, primary/metastatic site, objective response, total cycles of drug administration and Eastern Cooperative Oncology Group performance status (ECOG-PS). Peripheral blood tests were conducted before the initial cycle of drug administration and used to evaluate mGPS. Scores for mGPS were defined by combining serum CRP and Alb levels as follows: mGPS $0, \mathrm{Alb} \geq 3.5 \mathrm{~g} / \mathrm{dl}$ and CRP $\leq 0.5$ $\mathrm{mg} / \mathrm{dl}$; mGPS 1, (1) Alb $\geq 3.5 \mathrm{~g} / \mathrm{dl}$ and CRP $>0.5 \mathrm{mg} / \mathrm{dl}$ or (2) Alb $<3.5 \mathrm{~g} / \mathrm{dl}$ and CRP $\leq 0.5 \mathrm{mg} / \mathrm{dl} ;$ mGPS $2, \mathrm{Alb}<3.5 \mathrm{~g} / \mathrm{dl}$ and CRP $>0.5$ $\mathrm{mg} / \mathrm{dl}$. We allocated patients with $\mathrm{mUC}$ to undergo shGC and PEM therapies based on their mGPS score, and analyzed differences in cancer-specific (CSS) and progression-free (PFS) survival. In this study, CSS was designated as starting from when the initial drug was administered to when death was caused by cancer. PFS was designated as starting from the time when the initial drug was administered to when cancer was shown to progress.

Statistical analysis. The Fisher's exact test was useful in comparing differences in categorical variables. We used a Kruskal-Wallis test for ordinal and monotonic variables. Differences in CSS and PFS were evaluated using a Kaplan-Meier method. Bonferroni 

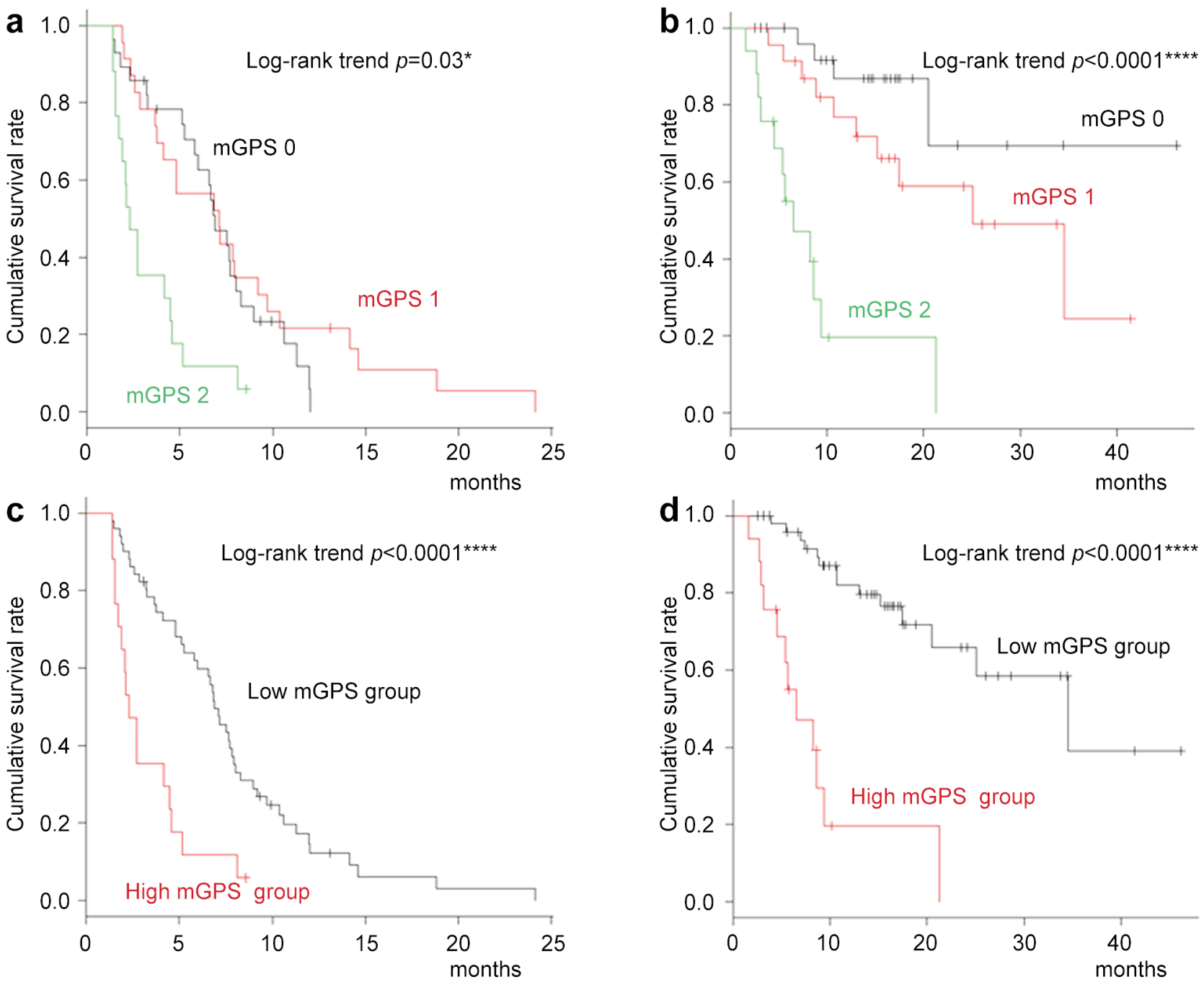

Figure 1. Kaplan-Meier curves of PFS and CSS in a first-line shGC treatment cohort. PFS (a) and CSS (b) of patients, grouped according to mGPS, are shown. Comparison of PFS and CSS between low and high mGPS groups are shown $(c, d)$. CSS, Cancer-specific survival; mGPS, modified Glasgow prognostic score; PFS, progression-free survival; shGC, short hydration gemcitabine and cisplatin.

adjustments were used for multiple testing. The correlation between mGPS and CSS or PFS was examined by log-rank trend test. Moreover, allocations of the two patient groups were based on mGPS: low (mGPS 0 or mGPS 1), and high (mGPS 2). Differences between two groups were assessed with a log-rank test. A Cox proportional hazard regression model was employed to analyze univariate and multivariate analyses. Statistical significance was when $p<0.05$. EZR for $\mathrm{R}$ was used for all statistical analyses $(\mathrm{R}$ Project, Vienna, Austria) (15).

\section{Results}

Characteristics of patients who received shGC. The characteristics of patients who received shGC are shown in Table I. They were allocated to the three groups based on
mGPS: mGPS 0, mGPS 1, and mGPS 2. Significant differences were not found between the three groups with regard to age, gender, and primary site. However, BMI, number of metastatic sites, ECOG-PS, objective response, and total cycles of shGC were significantly different across groups.

PFS and CSS of patients who received shGC. The PFS, based on mGPS, is shown in Figure 1a. The PFS of patients showing an mGPS of 0 was comparable to that of those with mGPS $1(p=1.000)$. The PFS of patients showing an mGPS of 2 was found to be significantly shorter than that shown by patients with an mGPS of 0 or $1 \quad(p<0.01$ and $<0.01$, respectively). The higher mGPS correlated with poorer PFS ( $p=0.027)$. 
in vivo $35: 2793-2800(2021)$

Table II. Univariate and multivariate analyses of baseline parameters, and cancer-specific survival in patients who received first-line shGC.

\begin{tabular}{|c|c|c|c|c|c|c|}
\hline \multirow[b]{2}{*}{ Parameters } & \multicolumn{3}{|c|}{ Univariate } & \multicolumn{3}{|c|}{ Multivariate } \\
\hline & HR & $95 \% \mathrm{CI}$ & $p$-Value & HR & $95 \% \mathrm{CI}$ & $p$-Value \\
\hline Age at start of $1^{\text {st }}$-line shGC, $\geq 70 v s .<70$ & 0.78 & $0.36-1.688$ & 0.5257 & - & - & - \\
\hline Gender, male $v s$. female & 0.47 & $0.14-1.58$ & 0.2256 & - & - & - \\
\hline ECOG-PS at start of $1^{\text {st-line }}$ shGC, $1 v s .0$ & 4.22 & $1.68-10.57$ & $<0.01 * *$ & 2.05 & $0.748-5.60$ & 0.16 \\
\hline $\begin{array}{l}\text { Visceral metastasis at start of } 1^{\text {st }} \text {-line shGC, } \\
\text { yes } v s \text {. no }\end{array}$ & 3.10 & $1.37-7.03$ & $<0.01 * *$ & 2.39 & $0.97-5.87$ & 0.06 \\
\hline mGPS at start of $1^{\text {st }-l i n e ~ s h G C, ~} 2$ vs. 0,1 & 4.19 & $2.254-7.78$ & $<0.001 * * *$ & 3.55 & $1.88-6.70$ & $<0.001 * * *$ \\
\hline
\end{tabular}

CI; Confidence interval, ECOG-PS; Eastern Cooperative Oncology Group Performance Status, HR; hazard ratio, mGPS; modified Glasgow prognostic score, shGC; short hydration gemcitabine and cisplatin. ${ }^{* *} p<0.01, * * * p<0.001$.

The CSS of the three groups is summarized in Figure 1b. Patients with mGPS 0 showed a CSS that was comparable with that of those with mGPS $1(p=0.342)$. The CSS of patients with an mGPS of 2 was found to be significantly shorter than that of those with mGPS 0 or $1(p<0.0001$ and $<0.001$, respectively). The higher mGPS tended to correlate with a poorer CSS $(p<0.0001)$. The PFS and CSS of the high and low mGPS groups are shown in Figure 1c and 1d. The high-mGPS group showed poor PFS and CSS compared with the low mGPS group.

Univariate and multivariate analyses of patients who received shGC. Table II shows univariate and multivariate statistical analyses of baseline parameters, and CSS in all 68 patients treated with first-line shGC. Age at the start of firstline shGC and also gender did not statistically correlate with CSS. ECOG-PS, visceral metastasis, and mGPS correlated with CSS in univariate analysis. Multivariate analysis revealed high mGPS as an independent risk factor $(\mathrm{HR}=3.55$; $p<0.001)$.

Characteristics of patients who received PEM. Table III outlines the characteristics of patients who underwent PEM, allocated to the three groups based on mGPS. Significant differences were not found in age, primary/metastatic site, BMI, first-line chemotherapy regimen, cycle of first-line chemotherapy, and objective response between the three groups. However, gender, ECOG-PS, and total cycles of PEM were significantly different.

PFS and CSS of patients who received PEM. Figure $2 \mathrm{a}$ shows a comparison of PFS based on mGPS. The PFS of patients with an mGPS of 0 was comparable to those with an mGPS of $1(p=1)$. The PFS of those patients with an mGPS of 2 was significantly shorter than that of patients with an mGPS of 0 or 1 ( $p<0.001$ and $<0.01$, respectively). A higher mGPS tended to correlate with a poorer PFS $(p=0.02)$. The CSS of the three groups is summarized in
Table III. Comparison of patients' characteristics in second-line PEM treatment cohort.

\begin{tabular}{|c|c|c|c|c|}
\hline Characteristics & $\begin{array}{c}\text { mGPS } 0 \\
(\mathrm{n}=23)\end{array}$ & $\begin{array}{c}\text { mGPS } 1 \\
(\mathrm{n}=23)\end{array}$ & $\begin{array}{c}\text { mGPS } 2 \\
(n=28)\end{array}$ & $p$-Value \\
\hline $\begin{array}{l}\text { Median age, } \\
\text { years (range) }\end{array}$ & $\begin{array}{c}72 \\
(56-84)\end{array}$ & $\begin{array}{c}70 \\
(50-84)\end{array}$ & $\begin{array}{c}75 \\
(46-84)\end{array}$ & 0.62 \\
\hline \multicolumn{5}{|l|}{ Gender, n (\%) } \\
\hline Male & 16 (69.6) & 16 (69.6) & 27 (96.4) & \multirow[t]{2}{*}{$<0.05^{*}$} \\
\hline Female & $7(30.4)$ & $7(30.4)$ & $1(3.6)$ & \\
\hline \multicolumn{5}{|l|}{ Primary site, $\mathrm{n}(\%)$} \\
\hline Upper urinary tract & $11(47.8)$ & $14(60.9)$ & $10(35.7)$ & \multirow[t]{2}{*}{0.21} \\
\hline Bladder & $12(52.2)$ & $9(39.1)$ & $18(64.3)$ & \\
\hline $\begin{array}{l}\text { Median BMI, } \\
\mathrm{kg} / \mathrm{m}^{2} \text { (range) }\end{array}$ & $\begin{array}{c}23.1 \\
(15.0-33.4)\end{array}$ & $\begin{array}{c}22.8 \\
(18.5-39.8)\end{array}$ & $\begin{array}{c}21.4 \\
(15.7-28.0)\end{array}$ & 0.06 \\
\hline \multicolumn{5}{|l|}{ Metastatic site, n (\%) } \\
\hline Lymph node alone & $10(43.5)$ & $9(39.1)$ & $11(47.8)$ & \multirow[t]{2}{*}{0.83} \\
\hline Visceral metastasis & $13(56.5)$ & $14(60.9)$ & $17(52.2)$ & \\
\hline \multicolumn{5}{|c|}{$\begin{array}{l}\text { First-line chemotherapy } \\
\text { regimen, } \mathrm{n}(\%)\end{array}$} \\
\hline $\begin{array}{l}\text { Gemcitabine and } \\
\text { cisplatin }\end{array}$ & $16(69.6)$ & $16(69.6)$ & $17(52.2)$ & \multirow[t]{2}{*}{0.78} \\
\hline $\begin{array}{l}\text { Gemcitabine and } \\
\text { carboplatin }\end{array}$ & $7(30.4)$ & $7(30.4)$ & $11(47.8)$ & \\
\hline $\begin{array}{l}\text { Median total cycle } \\
\text { of first-line } \\
\text { chemotherapy, } \\
\text { n (range) }\end{array}$ & $3(1-10)$ & $3(1-10)$ & $3(1-15)$ & 0.75 \\
\hline $\begin{array}{l}\text { Median duration of } \\
\text { first-line } \\
\text { chemotherapy, } \\
\text { months (range) }\end{array}$ & $\begin{array}{c}4.3 \\
(1.0-14.8)\end{array}$ & $\begin{array}{c}5.7 \\
(0.7-24.3)\end{array}$ & $\begin{array}{c}3.8 \\
(0.4-28.4)\end{array}$ & 0.37 \\
\hline \multicolumn{5}{|l|}{ ECOG-PS, n (\%) } \\
\hline 0 & $15(65.2)$ & $17(73.9)$ & $10(35.7)$ & \multirow[t]{3}{*}{$<0.05^{*}$} \\
\hline 1 & $8(34.8)$ & $5(21.7)$ & $15(53.6)$ & \\
\hline 2 & $0(0)$ & $1(4.4)$ & $3(10.7)$ & \\
\hline $\begin{array}{l}\text { Objective response, } \\
\mathrm{n}(\%)\end{array}$ & $7(30.4)$ & $5(21.7)$ & $4(14.3)$ & 0.384 \\
\hline $\begin{array}{l}\text { Median total cycles } \\
\text { of PEM, } \mathrm{n} \text { (range) }\end{array}$ & $\begin{array}{c}6 \\
(2-20)\end{array}$ & $\begin{array}{c}4 \\
(1-23)\end{array}$ & $\begin{array}{c}3 \\
(1-16)\end{array}$ & $<0.01 * *$ \\
\hline
\end{tabular}

BMI, Body mass index; ECOG-PS, Eastern Cooperative Oncology Group Performance Status; mGPS, modified Glasgow prognostic score; PEM, pembrolizumab. ${ }^{*} p<0.05,{ }^{*} p<0.01$, statistically significant. 

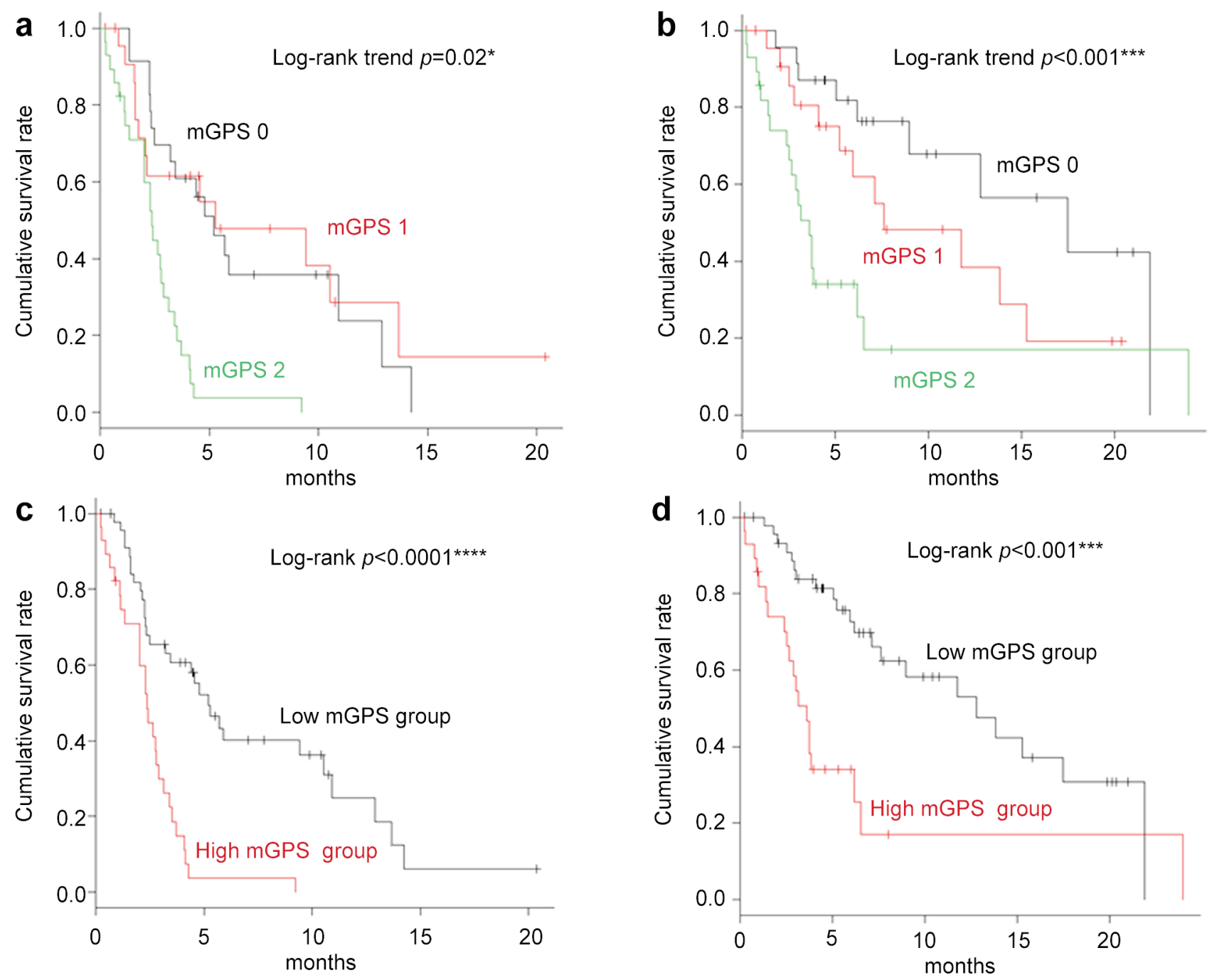

Figure 2. Kaplan-Meier curves of PFS and CSS in a second-line PEM treatment cohort. PFS (a) and CSS (b) of patients grouped according to $m G P S$ are shown. Comparisons of PFS and CSS between low and high mGPS groups are shown (c, $d)$. CSS, Cancer-specific survival; $m G P S$, modified Glasgow prognostic score; PEM, pembrolizumab; PFS, progression-free survival.

Figure 2b. Patients with mGPS 0 showed a CSS that was comparable with that of those with mGPS $1 \quad(p=0.35)$. Patients with mGPS 2 compared to those with mGPS 0 showed a CSS that was significantly shorter $(p<0.01)$. Patients with mGPS 2 tended to show a shorter CSS than those with mGPS 1 but a significant difference was not apparent $(p=0.06)$. A higher mGPS tended to correlate with a poorer CSS $(p<0.001)$. The PFS and CSS of the high- and low-mGPS groups are shown in Figure $2 \mathrm{c}$ and $2 \mathrm{~d}$. The highmGPS group showed poor PFS and CSS compared with the low-mGPS group.

Univariate and multivariate analyses of patients who received PEM. Univariate and multivariate statistical analyses of baseline parameters are shown in Table IV; the CSS of all 74 patients treated with second-line PEM is shown. ECOG-PS, visceral metastasis that occurred at the initiation of second-line PEM, and mGPS correlated with CSS in univariate analysis. Multivariate analysis revealed ECOG-PS (HR=2.96; $p<0.05)$ and high mGPS $(\mathrm{HR}=2.21$; $p<0.01)$ were found to be risk factors.

\section{Discussion}

In reference to other cancers, the utility of mGPS as a prognostic marker of the therapeutic effects of systemic therapy, including molecular-targeted drugs that are effective against advanced renal cell carcinoma (16), and the 
in vivo $35: 2793-2800(2021)$

Table IV. Univariate and multivariate analyses of baseline parameters, and cancer-specific survival in patients who received second-line PEM.

\begin{tabular}{|c|c|c|c|c|c|c|}
\hline \multirow[b]{2}{*}{ Parameters } & \multicolumn{3}{|c|}{ Univariate } & \multicolumn{3}{|c|}{ Multivariate } \\
\hline & HR & $95 \% \mathrm{CI}$ & $p$-Value & HR & $95 \% \mathrm{CI}$ & $p$-Value \\
\hline Age at start of $2^{\text {nd }}$-line PEM, $\geq 70 v s .<70$ & 1.03 & $1.00-1.07$ & 0.09 & - & - & - \\
\hline Gender, male $v s$. female & 1.53 & $0.67-3.45$ & 0.31 & - & - & - \\
\hline ECOG-PS at start of $2^{\text {nd }}-$ line PEM, 2 vs. 0,1 & 3.56 & $2.03-6.25$ & $<0.001 * * *$ & 2.96 & $1.18-7.43$ & $<0.05^{*}$ \\
\hline $\begin{array}{l}\text { Visceral metastasis at start of } 2^{\text {nd }}-\text { line PEM, } \\
\text { yes } v s \text {. no }\end{array}$ & 3.09 & $1.51-6.31$ & $<0.01 * *$ & 2.27 & $0.86-5.98$ & 0.10 \\
\hline mGPS at start of $2^{\text {nd }}-$ line PEM, 2 vs. 0,1 & 2.06 & $1.37-3.11$ & $<0.001 * * *$ & 2.21 & $1.30-3.78$ & $<0.01 * *$ \\
\hline
\end{tabular}

CI, Confidence interval; ECOG-PS, Eastern Cooperative Oncology Group Performance Status; HR, hazard ratio; mGPS, modified Glasgow prognostic score; PEM, pembrolizumab. ${ }^{*} p<0.05,{ }^{*} p<0.01$ statistically significant.

administration of nivolumab that is used for metastatic or recurrent head and neck squamous cell carcinoma, (17) have been reported. In urothelial cancer, the mGPS has been described as a prognostic factor of non-muscle invasive urothelial cancer used after a transurethral resection of the bladder, with or without intravesical therapy (18). A high mGPS score was also identified as a risk factor in the recurrence of cancer and as a predictive marker of overall survival in patients who underwent radical cystectomy (19, 20). In upper tract urothelial carcinoma, mGPS was found to be as a prognostic marker after nephroureterectomy (21). However, no report exists concerning mGPS and systemic therapy in mUC.

In this study, we used two retrospective cohorts to assess whether mGPS had value as a prognostic marker in those patients having mUC who received first-line shGC or second-line PEM. With regard to CSS, the prognosis of patients with mUC before shGC or PEM was predictive according to mGPS. As shown in Figure 1, because it was unable to distinguish between the PFS of patients with mUC and a mGPS 0 or 1 in each cohort, we analyzed whether mGPS in a high or low setting cutoff as mGPS 1 could be predictive of CSS and PFS. We found that mUC patients with mGPS 2 showed a poor prognosis in each cohort and that mGPS was able to identify patients with a poor prognosis in these settings. This study is the first report to suggest the efficacy of mGPS in the therapeutic stratification of patients with mUC.

It is known that ECOG-PS is an established marker for predicting the effects of systemic therapy (6). Above all, with regard to patients in ECOG-PS 2, the prognosis of those who received PEM was comparable with that of patients who received chemotherapy as second-line therapy (5). However, an important issue is that the subjective determination of ECOG-PS was mainly dependent on individual clinicians, which might have caused observational bias. On this point, mGPS could be considered an objective marker because it is scored based on the results of a blood examination. In our study, with regard to the mGPS 2 group in first-line shGC cohorts, no ECOG-PS 2 patients were enrolled. With regard to the mGPS 2 group in second-line PEM cohorts, even though approximately $90 \%$ of patients were ECOG-PS 0 or 1 , they could only receive three cycles of PEM. In these analyses, patients with mUC could be finely stratified according to mGPS; we could identify patients with a poor prognosis, although these could not be distinguished by ECOG-PS.

Identifying poor prognostic patients for systemic therapy is a very important issue for determining treatment strategies. The early application of palliative care was shown to enhance the quality of life and mood of cancer patients as well as also potentially improving the prognosis (22). Furthermore, according to an analysis by Greer et al. (23) of 151 newly diagnosed patients with metastatic lung cancer, receiving early palliative care together with standard oncological care might lead to optimizing when to administer the final chemotherapy and the uptake of hospice services compared to standard care alone. In other words, identifying the appropriate timing of instituting palliative therapy is beneficial for patients with a poor prognosis, even in receiving systemic treatment. In this study, approximately $80-90 \%$ of patients with mGPS 2 prior to first-line shGC and second-line PEM died within 12 months after the initiation of drug administration. A prognosis for all patients might not be necessary, however, clinicians should estimate the precise prognosis before starting systemic therapy. Stratification by using mGPS for predicting the prognosis is convenient and needs no additional examinations except for blood samples. Screening patients with mUC using mGPS might inform decision-making, including whether to change or stop drug therapy for those with a poor prognosis. A further largecohort prospective analysis is warranted to evaluate this strategic approach when selecting patients with mUC.

There are several advantages in this study. First, mGPS is an easily accessible marker for evaluating the condition of the patients. It requires only the result of blood examination 
and does not involve extra costs. Second, mGPS is objective compared to ECOG-PS because it does not reflect the subjectivity of the physician. Third, this is the first study to suggest the efficacy of mGPS in the therapeutic stratification of patients with mUC. The disadvantages of this study are that it does not provide the way to improve the prognosis. Whether improving mGPS leads to improved prognosis is still unclear.

Several limitations were apparent in this investigation. First, post-treatments with shGC and pre-or post-treatments with PEM were not united. Therefore, a selection bias in treatments was considered to influence the prognosis. Regardless, in patients with mUC who received systemic treatment, mGPS was assessed as an effective and practical prognostic biomarker for survival outcome.

In conclusion, we found that mGPS is a predictive marker of prognosis in patients who received first-line shGC or second-line PEM. The pretreatment mGPS is a feasible prognostic marker. It helps recognize the prognosis or therapeutic effects at the initiation of drug therapy and is useful for both patients and clinicians in their decision-making.

\section{Conflicts of Interest}

The Authors declare no conflicts of interest.

\section{Authors' Contributions}

All the Authors have read and approved the manuscript and agree with its submission to this journal. Details regarding authorship, conflicts of interest, and ethics approval are given in the accompanying Author Submission Requirement Form. The contribution of each author to the manuscript was sufficient enough for each to take public responsibility for appropriate portions of the content. Toshiki Etani and Taku Naiki made critical revisions of the manuscript. Takashi Nagai, Keitaro Iida, Yusuke Noda, Nobuhiko Shimizu, Yoshihiko Tasaki, Yoshihisa Mimura, Tomoki Okada, Rika Banno, Hiroki Kubota, Shuzo Hamamoto, Ryoske Ando, and Noriyasu Kawai carried out the acquisition of data, and coordinated and helped draft the manuscript. Yosuke Sugiyama conducted statistical analyses concerning the study. Takahiro Yasui supervised the study. All Authors read and approved the final manuscript.

\section{References}

1 Wong MCS, Fung FDH, Leung C, Cheung WWL, Goggins WB and $\mathrm{Ng} \mathrm{CF}$ : The global epidemiology of bladder cancer: a joinpoint regression analysis of its incidence and mortality trends and projection. Sci Rep 8(1): 1129, 2018. PMID: 29348548. DOI: $10.1038 / \mathrm{s} 41598-018-19199-\mathrm{z}$

2 Bladder Cancer - Cancer Stat Facts. Available at: https://seer. cancer.gov/statfacts/html/urinb.html [Last accessed on March 19, 2021]

3 von der Maase H, Hansen SW, Roberts JT, Dogliotti L, Oliver T, Moore MJ, Bodrogi I, Albers P, Knuth A, Lippert CM, Kerbrat P, Sanchez Rovira P, Wersall P, Cleall SP,
Roychowdhury DF, Tomlin I, Visseren-Grul CM and Conte PF: Gemcitabine and cisplatin versus methotrexate, vinblastine, doxorubicin, and cisplatin in advanced or metastatic bladder cancer: results of a large, randomized, multinational, multicenter, phase III study. J Clin Oncol 18(17): 3068-3077, 2000. PMID: 11001674. DOI: $10.1200 / J C O .2000 .18 .17 .3068$

4 Flaig TW, Spiess PE, Agarwal N, Bangs R, Boorjian SA, Buyyounouski MK, Chang S, Downs TM, Efstathiou JA, Friedlander T, Greenberg RE, Guru KA, Guzzo T, Herr HW, Hoffman-Censits J, Hoimes C, Inman BA, Jimbo M, Kader AK, Lele SM, Michalski J, Montgomery JS, Nandagopal L, Pagliaro LC, Pal SK, Patterson A, Plimack ER, Pohar KS, Preston MA, Sexton WJ, Siefker-Radtke AO, Tward J, Wright JL, Gurski LA and Johnson-Chilla A: Bladder cancer, Version 3.2020, NCCN clinical practice guidelines in oncology. J Natl Compr Canc Netw 18(3): 329-354, 2020. PMID: 32135513. DOI: 10.6004/ jncen.2020.0011

5 Bellmunt J, de Wit R, Vaughn DJ, Fradet Y, Lee JL, Fong L, Vogelzang NJ, Climent MA, Petrylak DP, Choueiri TK, Necchi A, Gerritsen W, Gurney H, Quinn DI, Culine S, Sternberg CN, Mai Y, Poehlein CH, Perini RF, Bajorin DF and KEYNOTE-045 Investigators: Pembrolizumab as second-line therapy for advanced urothelial carcinoma. N Engl J Med 376(11): 10151026, 2017. PMID: 28212060. DOI: 10.1056/NEJMoa1613683

6 Bellmunt J, Choueiri TK, Fougeray R, Schutz FA, Salhi Y, Winquist E, Culine S, von der Maase H, Vaughn DJ and Rosenberg JE: Prognostic factors in patients with advanced transitional cell carcinoma of the urothelial tract experiencing treatment failure with platinum-containing regimens. J Clin Oncol 28(11): 1850-1855, 2010. PMID: 20231682. DOI: 10.1200/JCO.2009.25.4599

7 Taguchi S, Akamatsu N, Nakagawa T, Gonoi W, Kanatani A, Miyazaki H, Fujimura T, Fukuhara H, Kume H and Homma Y: Sarcopenia evaluated using the skeletal muscle index is a significant prognostic factor for metastatic urothelial carcinoma. Clin Genitourin Cancer 14(3): 237-243, 2016. PMID: 26337653. DOI: $10.1016 /$ j.clgc.2015.07.015

8 Nagai T, Naiki T, Iida K, Nozaki S, Etani T, Sugiyama Y, Ando R, Yanase T, Chaya R, Moritoki Y, Kobayashi D, Akita H, Okamura $\mathrm{T}$ and Yasui T: Skeletal muscle mass reduction velocity as a simple prognostic indicator for patients with metastatic urothelial carcinoma receiving second-line chemotherapy. Asian Pac J Cancer Prev 20(10): 2995-3000, 2019. PMID: 31653146. DOI: 10.31557/APJCP.2019.20.10.2995

9 Seah JA, Leibowitz-Amit R, Atenafu EG, Alimohamed N, Knox JJ, Joshua AM and Sridhar SS: Neutrophil-lymphocyte ratio and pathological response to neoadjuvant chemotherapy in patients with muscle-invasive bladder cancer. Clin Genitourin Cancer 13(4): e229-e233, 2015. PMID: 25777682. DOI: 10.1016/ j.clgc.2015.02.001

10 Etani T, Naiki T, Sugiyama Y, Nagai T, Iida K, Noda Y, Shimizu N, Tasaki Y, Mimura Y, Okada T, Banno R, Kubota H, Hamamoto $\mathrm{S}$, Ando R, Kawai $\mathrm{N}$ and Yasui T: Low geriatric nutritional risk index as a poor prognostic marker for secondline pembrolizumab treatment in patients with metastatic urothelial carcinoma: a retrospective multicenter analysis. Oncology 98(12): 876-883, 2020. PMID: 32862183. DOI: 10.1159/000508923

11 McMillan DC, Forrest LM, O'Gorman P, Angerson WJ and McArdle CS: Performance status of male and female advanced 
cancer patients is independently predicted by mid-upper arm circumference measurement. Nutr Cancer 42(2): 191-193, 2002. PMID: 12416259. DOI: 10.1207/S15327914NC422_7

12 Koike Y, Miki C, Okugawa Y, Yokoe T, Toiyama Y, Tanaka K, Inoue $\mathrm{Y}$ and Kusunoki M: Preoperative $\mathrm{C}$-reactive protein as a prognostic and therapeutic marker for colorectal cancer. J Surg Oncol 98(7): 540-544, 2008. PMID: 18937231. DOI: 10.1002/ jso.21154

13 Qi F, Xu Y, Zheng Y, Li X and Gao Y: Pre-treatment Glasgow prognostic score and modified Glasgow prognostic score may be potential prognostic biomarkers in urological cancers: a systematic review and meta-analysis. Ann Transl Med 7(20): 531, 2019. PMID: 31807513. DOI: 10.21037/atm.2019.09.160

14 Naiki T, Sugiyama Y, Tasaki Y, Iida K, Etani T, Hamamoto S, Nagai T, Nozaki S, Ando R, Kawai N and Yasui T: Efficacy of a newly modified short hydration method for gemcitabine and cisplatin combination chemotherapy in patients with urothelial carcinoma. Oncology 98(9): 612-620, 2020. PMID: 32485713. DOI: $10.1159 / 000506992$

15 Kanda Y: Investigation of the freely available easy-to-use software 'EZR' for medical statistics. Bone Marrow Transplant 48(3): 452-458, 2013. PMID: 23208313. DOI: 10.1038/bmt. 2012.244

16 Ohmura H, Uchino K, Kajitani T, Sakamoto N and Baba E: Predictive value of the modified Glasgow Prognostic Score for the therapeutic effects of molecular-targeted drugs on advanced renal cell carcinoma. Mol Clin Oncol 6(5): 669-675, 2017. PMID: 28515920. DOI: 10.3892/mco.2017.1205

17 Matsuki T, Okamoto I, Fushimi C, Sawabe M, Kawakita D, Sato H, Tsukahara K, Kondo T, Okada T, Tada Y, Miura K, Omura G and Yamashita T: Hematological predictive markers for recurrent or metastatic squamous cell carcinomas of the head and neck treated with nivolumab: A multicenter study of 88 patients. Cancer Med 9(14): 5015-5024, 2020. PMID: 32441463. DOI: $10.1002 / \mathrm{cam} 4.3124$

18 Kimura S, D' Andrea D, Soria F, Foerster B, Abufaraj M, Vartolomei MD, Iwata T, Karakiewicz PI, Rink M, Gust KM, Egawa S and Shariat SF: Prognostic value of modified Glasgow Prognostic Score in non-muscle-invasive bladder cancer. Urol Oncol 37(3): 179.e19-179.e28, 2019. PMID: 30580906. DOI: 10.1016/j.urolonc.2018.11.005

19 Ferro M, De Cobelli O, Buonerba C, Di Lorenzo G, Capece M, Bruzzese D, Autorino R, Bottero D, Cioffi A, Matei DV, Caraglia M, Borghesi M, De Berardinis E, Busetto GM,
Giovannone R, Lucarelli G, Ditonno $\mathrm{P}$, Perdonà $\mathrm{S}$, Bove $\mathrm{P}$, Castaldo L, Hurle R, Musi G, Brescia A, Olivieri M, Cimmino A, Altieri V, Damiano R, Cantiello F, Serretta V, De Placido S, Mirone V, Sonpavde G and Terracciano D: Modified Glasgow Prognostic Score is associated with risk of recurrence in bladder cancer patients after radical cystectomy: a multicenter experience. Medicine (Baltimore) 94(42): e1861, 2015. PMID: 26496339. DOI: 10.1097/MD.0000000000001861

20 Miyake M, Morizawa Y, Hori S, Marugami N, Iida K, Ohnishi K, Gotoh D, Tatsumi Y, Nakai Y, Inoue T, Anai S, Torimoto K, Aoki K, Tanaka N, Shimada K, Konishi N and Fujimoto K: Integrative assessment of pretreatment inflammation-, nutrition, and muscle-based prognostic markers in patients with muscleinvasive bladder cancer undergoing radical cystectomy. Oncology 93(4): 259-269, 2017. PMID: 28647740. DOI: $10.1159 / 000477405$

21 Soria F, Giordano A, D’Andrea D, Moschini M, Rouprêt M, Margulis V, Karakiewicz PI, Briganti A, Bensalah K, Mathieu R, Chlosta P, Babjuk M, Glybochko PV, Enikeev DV, Remzi M, Gust K, Gontero P and Shariat SF: Prognostic value of the systemic inflammation modified Glasgow prognostic score in patients with upper tract urothelial carcinoma (UTUC) treated with radical nephroureterectomy: Results from a large multicenter international collaboration. Urol Oncol 38(6): 602.e11-602.e19, 2020. PMID: 32037197. DOI: 10.1016/ j.urolonc.2020.01.004

22 Temel JS, Greer JA, Muzikansky A, Gallagher ER, Admane S, Jackson VA, Dahlin CM, Blinderman CD, Jacobsen J, Pirl WF, Billings JA and Lynch TJ: Early palliative care for patients with metastatic non-small-cell lung cancer. N Engl J Med 363(8): 733-742, 2010. PMID: 20818875. DOI: 10.1056/ NEJMoa 1000678

23 Greer JA, Pirl WF, Jackson VA, Muzikansky A, Lennes IT, Heist RS, Gallagher ER and Temel JS: Effect of early palliative care on chemotherapy use and end-of-life care in patients with metastatic non-small-cell lung cancer. J Clin Oncol 30(4): 394400, 2012. PMID: 22203758. DOI: 10.1200/JCO.2011.35.7996

Received March 21, 2021

Revised June 1, 2021

Accepted June 4, 2021 